\title{
EL PRINCIPIO DE PRESENCIA EQUILIBRADA EN EL ART. 44 BIS DE LA LOREG Y EL DERECHO DE ACCESO A LOS CARGOS PÚBLICOS EN CONDICIONES DE IGUALDAD: ANÁLISIS CRÍTICO DE LA ÚLTIMA REFORMA DE LA LOREG ${ }^{1}$
}

\author{
MARÍA VICENTA GARCÍA SORIANO \\ Universitat de Valencia-Estudi General
}

Fecha de recepción: 6-10-2008.

Fecha de aceptación: 27-10-2008.

\section{Introducción}

La Constitución española, en su art. 1.1, recoge la igualdad como valor, en el art. 14 prohíbe todo tipo de discriminación y, en el art. 9.2, impone a los Poderes Públicos la obligación de promover las condiciones para la igualdad efectiva y de remover los obstáculos que impidan o dificulten su plenitud ${ }^{2}$, así como facilitar la participación de todos los ciudadanos en la vida política. Por su parte, en el ámbito electoral, el art. 23.2 CE concreta el principio de igualdad. Pese a dichas previsiones, tres décadas después de la entrada en vigor de la Carta Magna, no se ha logrado la efectiva participación de la mujer en la vida política ${ }^{3}$.

1. Este trabajo se ha realizado en el marco del proyecto $\mathrm{I}+\mathrm{D}$ «El derecho a la participación política de hombres y mujeres: consecuencias de la aplicación de la LOI a los procesos electorales» (Ref. 808/2008), financiado por Ministerio de Trabajo, Instituto de la Mujer.

2. Figueruelo BurRiEZA, A., et alter: El reto de la efectiva igualdad de oportunidades, Granada 2006.

3. Elvira Perales, A.: «La participación política de las mujeres», en Palomar Olmedo, A.: El tratamiento de género en el ordenamiento español, Valencia, 2005. 
La escasa presencia de la mujer en la vida política no es un fenómeno exclusivo de España ${ }^{4}$, sino común en la mayoría de países de nuestro entorno, por ello, alcanzar mayores cotas de poder por parte de la mujer en el acceso y desempeño del poder forma parte de los proyectos de los partidos y gobiernos democráticos y las fuerzas políticas se ven obligadas a recoger las demandas de participación de las mujeres en los asuntos públicos ${ }^{5}$. Para conseguirlo, junto con la asunción por parte de algunos partidos de la decisión de fomentar en sus candidaturas la presencia de las mujeres, se han adoptado distintos instrumentos a lo largo de las últimas décadas: la aplicación por ley de un sistema de cuotas electorales, que obliguen a los partidos a reservar un porcentaje de puestos en las listas para las mujeres a la hora de confeccionar las candidaturas, -e incluso, en algunos casos se ha aplicado un sistema de listas paritarias ${ }^{6}$, hasta la reciente opción por parte del legislador español por la presencia equilibrada de hombres y mujeres en las candidaturas.

4. Vid. Union Interparlamentaria, Plan de acción para corregir los actuales desequilibrios en la participación de hombres y mujeres en la vida política, Ginebra, 1994.

Referencia obligada resulta la Convención sobre los derechos políticos de la Mujer, y la Convención sobre la eliminación de todas las formas de discriminación contra la mujer (CEDAW), especialmente su art. 3, en el que se establece la obligación de todos los Estados parte de tomar medidas, incluso de carácter legislativo, para garantizar a la mujer el ejercicio y el goce de determinados derechos fundamentales. En el ámbito de la política se refiere al establecimiento de cupos o cuotas electorales femeninas mediante medidas legislativas.

Puede consultarse en http://www.un.org/womenwatch/daw/cedaw.htm.

Por su parte, el Parlamento Europeo ha aprobado un informe no vinculante ( Por una mayor participación de mujeres en la vida política», 2006) en el que pone de manifiesto la marcada desigualdad de género existente en la política actual. El texto presentado al pleno instaba a los partidos políticos a que garantizasen «que la representación de ambos sexos se encuentra comprendida entre un mínimo de un $40 \%$ y un máximo de un $60 \%$ en sus listas». Sin embargo esta parte fue enmendada y se sustituyó por que «promuevan una participación equilibrada de ambos sexos en sus listas de candidatos» (enmienda 19, aprobada por 288 votos a favor, 191 en contra y 29 abstenciones).

5. Verge T.: «Mujer y partidos políticos en España: las estrategias de los partidos y su impacto institucional: 1978-2004», Revista Española de Investigaciones Sociológicas, 115 (2006), pp. 165-96.

6. FAVOREAU, L.: «Principio de igualdad y representación política de las mujeres: cuotas, paridad y Constitución», Revista Española de Derecho Constitucional, 50 (1997), pp. 1328. Puede consultarse sobre esta cuestión: COBO. R.: «Política feminista y democracia paritaria», Leviatán. Revista de los hechos e ideas, 80 (2000) y SAAVEDRA RUIZ, P.: Hacia una democracia paritaria. Hacia una revisión de las leyes electorales vigentes, Madrid, 1999. SeVilla Merino, J., Ventura Franch, A: «Fundamento Constitucional de la Ley Orgánica 3/2007, de 22 de marzo, para la igualdad efectiva de mujeres y hombres. Especial referencia a la participación política», Revista del Ministerio de Trabajo y Asuntos Sociales, 2 (2007). 
Sin embargo, el recurso a estas medidas no ha contado con el apoyo de todas las fuerzas políticas; al contrario, no han faltado voces que mantienen que han de ser las mujeres las que, por sí mismas, consigan un puesto en las listas; sostienen que no es necesario articular ningún tipo de medidas, pues consideran que el aumento de la presencia de mujeres en los Parlamentos es un hecho probado ${ }^{7}$. Nada más lejos de la realidad, cuyos datos desmienten dicha afirmación: tal y como puede observarse de los datos extraídos de la página web del Instituto de la Mujer, el número de mujeres que resultan electas en las distintas convocatorias electorales no ha llegado a alcanzar, en la mayoría de los casos, ni un tercio de los puestos a cubrir. La situación en la que nos encontrábamos en el momento en que se aprueba la LO 3/2007 para la igualdad efectiva, que conllevó las reformas de la LO 5/1985 de Régimen Electoral General (LOREG), que vamos a tratar a continuación, distaba mucho de la igualdad efectiva de mujeres y hombres sino que el escenario era el resultado de una discriminación duplicada: cuantitativa, escaso número de mujeres en las listas; y cualitativa, su mal posicionamiento ${ }^{8}$, con la que era necesario acabar y para ello había que arbitrar las medidas oportunas para que las mujeres pudieran, efectivamente, acceder a los cargos públicos en condiciones de igualdad.

\section{El derecho de acceso a los cargos públicos en condiciones de igualdad y la remoción de obstáculos para la efectiva participación de la mujer}

Con carácter previo al análisis de las medidas establecidas en el nuevo art. 44 bis LOREG, consecuencia de la aprobación de la Ley Orgánica 3/2007 para la igualdad efectiva de mujeres y hombres, recordemos que, el derecho de sufragio pasivo, se considera como un derecho subjetivo de participación y su ejercicio puede estar sometido a requisitos distintos a los previstos para el ejercicio de la vertiente activa del derecho. El art. 23.2 CE reconoce el derecho de acceso a cargos públicos solamente a los «ciudadanos», lo que permite sostener que únicamente pueden ser titulares de este derecho las personas físicas ${ }^{9}$.

Por otro lado, la proclamación de la candidatura, y por ello a la presentación misma, válida y eficazmente realizada, se liga la expectativa del can-

7. Rey MartíneZ, F. «Cuotas electorales reservadas a mujeres y Constitución», Aequalitas, 1 (1999), p. 56, mantiene esta última postura.

8. Ver, por ejemplo, GARCíA DE LEON, M. A.: Élites discriminadas, Barcelona, 1994; VALCARCEL, A.: El techo de cristal. Los obstáculos para la participación de las mujeres en el poder político, Madrid, 1994.

9. Entre otras, SSTC 53/1982, 5/1983, 23/1983, 51/1984, 63/1987, 27/1988.

Feminismo/s 12, diciembre 2008, pp. 135-154 
didato, garantizada por el ordenamiento de que, de no quedar afectada su propuesta por defectos que no hayan sido oportunamente subsanados, será finalmente así proclamado por el órgano de la Administración electoral. Se sigue de lo dicho que, con anterioridad a la publicación de las candidaturas presentadas, no puede aún hablarse, en rigor, de candidatos electorales reconocidos como tales por la Administración, existiendo sólo un acto inicial de propuesta a cargo de los promotores de la candidatura y una mera recepción administrativa del escrito que la incorpora. Aún no eficaz, por lo tanto, este acto primero de los promotores -y no siendo todavía, por lo mismo, «candidato» quien haya sido así propuesto- nada impide, de principio, el que, antes del acto formal mediante el que se dispone por la Junta la publicación de las candidaturas, pero aún dentro del plazo para su presentación, se puedan controvertir por sus mandantes los actos realizados por los representantes electorales con arreglo a las normas comunes antes citadas y a efectos, por ejemplo, de depurar eventuales extralimitaciones en el desempeño del poder conferido. En tal supuesto no se afectaría al derecho fundamental de quien todavía no ha sido tenido por candidato mediante la correspondiente publicación.

El Tribunal Constitucional, en la STC 12/2008, recordará que no se trata de una condición de elegibilidad o una causa de inelegibilidad, sino una condición impuesta a los partidos políticos y a las agrupaciones de electores que no son sujetos del derecho de sufragio pasivo. El art. 23.2 CE consagra un derecho de acceso en condiciones de igualdad a los cargos públicos, pero no se trata de un derecho indiscriminado sino de configuración legal, como señala expresamente el inciso final del precepto, y su satisfacción requiere, por tanto, el cumplimiento de los requisitos determinados por las leyes. No se lesiona, pues, este precepto si la exigencia de los requisitos establecidos con carácter general por las leyes se aplica motivadamente con criterios razonables y en términos de generalidad que excluyan toda idea de discriminación personal o que supongan, por parte de la Administración electoral, restricciones innecesarias para el ejercicio de este derecho fundamental ${ }^{10}$. Según ha mantenido el Tribunal Constitucional en este punto, la elegibilidad se delimita por lo que dice el art. 70.1 de la C.E. y, por remisión de la misma, por la LOREG. Es la ley, por tanto, respetando, por un lado, el contenido de inelegibilidad mínimo que establece la norma constitucional y sin que quede afectada la esencia del derecho, configurará, desde esta vertiente, la elegibilidad ${ }^{11}$. Queda claro, pues que para el ejercicio eficaz del derecho de sufragio pasivo, según la propia

10. STC $24 / 1989$.

11. STC $45 / 1983$.

Feminismo/s 12, diciembre 2008, pp. 135-154 
Constitución prescribe, no puede actuarse sino «con los requisitos que señalen las Leyes» (art. 23.2) ${ }^{12}$.

Por consiguiente, el principio de igualdad, garantizado por la Constitución, ha de verificarse dentro del sistema electoral que libremente sea determinado por el legislador, impidiendo las diferencias discriminatorias, pero a partir de las reglas del sistema y no por referencia a cualquier otro. La capacidad electoral pasiva se encuentra sometida al cumplimiento de una serie de requisitos fijados en la LOREG tal y como ocurre en la mayoría de legislaciones que requieren ciertas condiciones especiales para poderse presentar a las elecciones ${ }^{13}$, a lo que hay que sumar el cumplimiento de ciertos requisitos por parte de las candidaturas para que éstas puedan ser proclamadas y concurrir a las elecciones. El problema se planteó, a la hora de aplicarse el art. 44 bis LOREG respecto de la constitucionalidad de los requisitos exigidos por las leyes electorales para la confección de las candidaturas, consecuencia de la adopción por parte del legislador de las medidas que consideró más adecuadas para alcanzar la igualdad efectiva, en particular, la inclusión de medidas que permitan la efectiva participación de las mujeres, dudas que ya han sido resueltas por el Tribunal Constitucional en la STC 12/2008.

\section{Las diversas medidas para el acceso de las mujeres a los cargos públicos en condiciones de igualdad y su encaje constitucional}

\subsection{El sistema de cuotas. Posiciones a favor y en contra}

Como ya se ha señalado, las cuotas de participación no son una meta a conseguir, la solución a la falta de participación femenina, sino instrumentos efectivos a corto plazo que pueden justificarse por dos tipos de razones: en cuanto al fin, las cuotas pretenden una sociedad más igualitaria; en cuanto al medio, facilitar el acceso a puestos socialmente importantes a la mujer puede ser un instrumento eficaz para lograr ese fin, si no de manera directa, sí como símbolo de que se puede romper el llamado 'techo de cristal'14.

La reserva de un determinado número de puestos para las mujeres es un ejemplo de acción positiva, es decir, de adopción de medida desigual a favor de la igualdad de un colectivo discriminado, el problema de este tipo de medidas en España ha sido su compatibilidad con la Constitución, pues, a diferencia de lo que ocurre en otros textos constitucionales (verbi gratia la

12. STC $73 / 1987$.

13. García Soriano, M.V.: Elementos de Derecho Electoral, 2 ed. Valencia, 2005, p. 65.

14. Así lo sostiene Ruiz Miguel, A.: «Paridad electoral y cuotas femeninas», Claves de la Razón Práctica, 94 (1999). 
Constitución francesa) nuestra Constitución no prevé explícitamente la existencia de cuotas electorales ${ }^{15}$, de modo que, para algunos autores, éstas tienen difícil encaje constitucional, considerando que la interpretación sistemática o finalista no contribuye a despejar la incertidumbre sino a agravarla ${ }^{16}$.

Respecto de la reserva de un determinado número de puestos en las listas, la doctrina se había dividido entre quienes se mostraban favorables a la inclusión de un sistema de cuotas en las distintas leyes electorales por considerarlo perfectamente compatible con la Carta Magna ${ }^{17}$ y, quienes se manifestaban, por razones jurídicas, poco favorables a las fórmulas coactivas de representación política preferencial a favor de las mujeres, entre otras consideraciones porque las cuotas toman como criterio de diferenciación jurídica las diferencias de sexo, cuando, señalaban, precisamente son esas diferencias las que se desea excluir ${ }^{18}$. Se objetaron las cuotas por las más variadas razones. A saber:

a) Porque pueden producir el efecto boomerang sobre los grupos a los que se protege, amén de los posibles motivos de inconstitucionalidad ${ }^{19}$. (Permítasenos recordar que, en realidad, no son las diferencias, sino la discriminación lo que se desea erradicar, si bien estamos de acuerdo en que tal vez hubiese otra vía jurídicamente más irreprochable. Como sostiene Ruiz Miguel, «el defecto de la norma que estableciera un sistema de cuotas residiría no en la reserva como tal sino sólo en el hecho de no establecerla para cualquiera de los dos sexos» ${ }^{20}$, esto es, con carácter bidireccional).

15. Sobre el sistema de cuotas puede consultarse, SEVILLA MERINO, J: «Mujeres y hombres en la vida política: las cuotas para mujeres en los partidos políticos», Aequalitas, 19 (2006), pp. 50-60; SÁNCHEZ-RodrígueZ, F., y PUnZÓN MORAlEDA, J.M.: «Paridad, cuotas y acción positiva a favor de la mujer: tres reflexiones desde la legitimidad social y la norma jurídica», Revista Jurídica de Castilla la Mancha, 38 (2005), pp. 155-200; ARANDA ÁLVAREZ, E.: «Discriminación por razón de sexo en el ámbito político: los problemas de las cuotas electorales», en PÉREZ ROYO, J., et alter: Derecho Constitucional para el s. XXI, Actas del VIII Congreso Iberoamericano, 2006.

16. En este sentido REY MARTínEZ, F: «Cuotas electorales reservadas a mujeres...», op.cit., p. 53.

17. Salazar Benítez, O.: Las cuotas electorales femeninas: una exigencia del principio de igualdad sustancial, Córdoba, 2001; AGUIAR, F: «A favor de las cuotas femeninas», Claves de la Razón práctica, 116 (oct.2001), pp. 28-35.

18. Rey MARTíneZ, F.: «Cuotas electorales...», op.cit., p. 55 y ss, que mantenía que las cuotas podrían ser contraproducentes pues reforzarían el problema de la desigualdad e reintroducirían problemas de paternalismo.

19. Ibíd., p. 57: se lesiona el derecho de los partidos políticos a presentar los candidatos que deseen, se comprometen la libertad de asociación (art. $22 \mathrm{CE}$ ) la ideológica (art.16.1 CE) y la libertad de los partidos (art. $6 \mathrm{CE}$ ).

20. Ruiz Miguel, A.: «La representación democrática de las mujeres», Anales de la Cátedra Francisco Suárez, 35 (2001), p. 259. 
b) Por considerar que violan el derecho a no ser discriminados por razón de sexo, pues aducen que con la aplicación de las cuotas no se está ante una legítima igualdad de oportunidades sino ante una igualdad de resultados; además, las mujeres no constituyen un grupo minoritario por lo que se vulneraría, con esta medida paternalista, el art. $14 \mathrm{CE}^{21}$. Quienes se mostraban contrarios a las cuotas sostenían que distinguir a los candidatos por su sexo lesionaría gravemente el dogma de la unidad y la homogeneidad del cuerpo electoral y la paridad no es igualdad, pues la paridad conduciría a una democracia de hombres y mujeres representados al 50\%, sin embargo, la igualdad en una democracia da como resultado ciudadanos intercambiables ${ }^{22}$.

c) Se mantenía que el derecho de sufragio activo resultaría tocado si las candidaturas han de ser conformadas respetando la paridad de sexos y, en no menor medida se ve afectado el derecho de sufragio pasivo del art. 23.2 CE, si al grupo de los in eligendo que se oferta al cuerpo electoral sólo se accede si el acceso resulta compatible con la paridad de sexos, de modo que los candidatos además de no incurrir en causa alguna de inelegibilidad deben estar a lo que resulte del reparto por sexos, con lo aleatorio que ello podría ser tanto en términos demográficos como de disponibilidad.

d) Asimismo, diversos autores han sostenido que la imposición legal de cuotas electorales de género condiciona la libertad de los partidos políticos (reconocida en el art. $6 \mathrm{CE}$ ), concretada en este caso, en la libertad de candidatura. Se basan en que los partidos políticos no son poderes públicos, no son órganos del Estado sino «entes privados de base asociativa», como los define la Exposición de Motivos de la LO 6/2002, producto del ejercicio de la libertad de asociación ${ }^{23}$. El derecho de asociación es un derecho fundamental reconocido en el art. $22 \mathrm{CE}$ y los partidos gozan de la protección de este precepto que conforma el núcleo básico de su régimen constitucional ${ }^{24}$, si bien no son enteramente asimilables a otras asociaciones al ser asociaciones de relevancia constitucional ${ }^{25}$. La presentación de candidaturas y la formación de listas para concurrir a los comicios forma parte del núcleo duro del derecho de estas asociaciones, esta facultad de formar y presentar candidaturas es consustancial a éstos $^{26}$, sin las que las elecciones no son concebibles, de modo que los requi-

21. Rey MartíneZ, F.: «Cuotas electorales...», op. cit., p. 58.

22. Ibíd., p. 57.

23. STC $10 / 1983$.

24. STC $85 / 1986$.

25. STC 3/1981.

26. Ver STC 10/83.

Feminismo/s 12, diciembre 2008, pp. 135-154 
sitos que las leyes impongan a la confección y presentación de candidaturas tienen un impacto directo sobre la actividad asociativa de los partidos ${ }^{27}$.

e) Otro de los argumentos más comunes utilizados frente a la imposición de cuotas ha sido la insistencia de que con esta medida se toma en consideración sólo el sexo de la persona y prescinden de los méritos, o los cercenan, a la hora de decidir quién formará parte de una candidatura. Este argumento resulta fácilmente rebatible por cuanto los criterios para la selección de quiénes pasarán a integrar una candidatura no suelen caracterizarse por su imparcialidad y objetividad en aras de buscar el candidato/a más capacitado; no obstante, aunque así fuera, parece que estén defendiendo que siempre, o la mayoría de las veces, el candidato hombre ostenta más fácilmente dichas cualidades que una candidata, lo cual no se ha demostrado. Sí es cierto, no obstante, que en ciertos casos faltan mujeres en los partidos, sin embargo, la política de cuotas podría conseguir el incremento de dicha presencia ${ }^{28}$.

Aunque el actual art. 44 bis LOREG no establece un sistema de cuotas sino que aplica el principio de participación equilibrada, hemos considerado interesante traer a colación los principales argumentos en contra de la introducción de cuotas electorales, porque casi todos ellos se utilizan tanto en la cuestión como en el recurso de inconstitucionalidad presentados frente a las modificaciones de la LOREG, introducidas por el art. 44 bis, y que analizaremos más adelante, para sustentar la inconstitucionalidad de dicho precepto.

\subsection{Las «listas cremallera» en las leyes electorales autonómicas. \\ Una medida sospechosa de inconstitucionalidad}

En España, con carácter previo a la LO 37/2007, ya se habían tomado algunas medidas en el ámbito autonómico para introducir la cuota de género en las candidaturas, en su modalidad de 'listas cremallera'29. Así, en la Exposición de motivos de la Ley electoral balear 6/2002, se afirmaba que con ella se apostaba por una acción positiva que rompiese con la dinámica existente e hiciese realidad la participación equitativa de la mujer en la política. Con dicha finalidad, el art. 16.4 establecía: «Las candidaturas electorales deberán contener una presencia equilibrada de hombres y mujeres. Las listas se integrarán por candidatos de uno y otro sexo ordenados de forma alternativa». Por su parte, la Ley electoral de Castilla-La Mancha 11/2002, de 27 de junio su art. 23.1 bis,

27. ARCE JANARIZ, A.: «Primeras leyes en España sobre paridad electoral», Diario La Ley, 5617 (septiembre 2002), p. 1699, Tomo 5 (Consultado en formato electrónico, p. 4.).

28. Ruiz Miguel, A.: «La representación democrática...», op. cit., p. 260.

29. Ver ARCE JANARIZ, A.: «Primeras leyes en España sobre paridad electoral», op. cit, p. 4 y ss. 
añadió, al efecto de garantizar el principio de igualdad en la representación política, que en las candidaturas ocuparían los de un sexo los puestos pares y los del otro los impares. Las previsiones contenidas en estas leyes, entre otros motivos, fueron criticadas por implantar cuotas y no esperar a que se modificara la LOREG, incorporando la distribución porcentual de puestos 40-60\%.

La Ley 5/1990, de 15 de junio, de Elecciones al Parlamento Vasco, modificada por la Ley 4/2005, de 18 de febrero, para la Igualdad de Mujeres y Hombres, añade un párrafo, con el número 4, al artículo 50 de la Ley 5/1990, de 15 de junio, de Elecciones al Parlamento Vasco, con el siguiente tenor:

«4. Las candidaturas que presenten los partidos políticos, federaciones, coaliciones o agrupaciones de personas electoras estarán integradas por al menos un 50\% de mujeres. Se mantendrá esa proporción en el conjunto de la lista de candidatos y candidatas y en cada tramo de seis nombres. Las juntas electorales del territorio histórico competentes sólo admitirán aquellas candidaturas que cumplan lo señalado en este artículo tanto para las personas candidatas como para las suplentes.»

Y el artículo 6 bis de la Ley 1/1987, de Elecciones para las Juntas Generales de los tres territorios históricos, queda redactado de la forma siguiente:

«1. Las candidaturas que presenten los partidos políticos, federaciones, coaliciones o agrupaciones de personas electoras estarán integradas por al menos un 50\% de mujeres. Se mantendrá esa proporción en el conjunto de la lista de candidatos y candidatas y en cada tramo de seis nombres. Las Juntas Electorales de Zona competentes sólo admitirán aquellas candidaturas que cumplan lo señalado en este artículo tanto para las personas candidatas como para las suplentes.»

La ley 5/2005 de 8 de abril modifica la Ley 1/1986, de 2 de enero, Electoral de Andalucía, el art. 23.1 y prevé lo siguiente:

«1. La presentación de candidaturas, en la que se alternarán hombres y mujeres, habrá de realizarse entre el decimoquinto y el vigésimo días posteriores a la convocatoria, mediante listas que deben incluir tantos candidatos como escaños a elegir por cada circunscripción y, además, cuatro candidatos suplentes, expresándose el orden de colocación.»

La constitucionalidad ${ }^{30}$ de dichas leyes electorales se cuestionó por una parte de la doctrina que consideraba que tales previsiones constituían una evidente restricción a la libertad de ser elegido que forma parte del derecho de sufragio

30. En el caso de las leyes de Castilla-La Mancha y de Baleares, fue el Gobierno el que promovió un recurso de inconstitucionalidad, lo que supuso la paralización de su aplicación; en el caso del país Vasco, el recurso fue promovido por 62 diputados del Grupo Popular. En el caso de Andalucía, más de 50 diputados del Grupo Popular también promovieron, contra la misma, un recurso de inconstitucionalidad.

Feminismo/s 12, diciembre 2008, pp. 135-154 
pasivo en cuanto «que determinados potenciales candidatos serán eliminados de las listas por formar parte del sexo sobrerrepresentado $»^{31}$. Por otro lado, se aseguraba que, hasta ese momento, las limitaciones impuestas por la LOREG en relación con la posibilidad de formar parte de una candidatura, eran sólo temporales (la minoría de edad desaparece al cumplir los 18 años, la inelegibilidad cuando el candidato cesa en el cargo...), pero las restricciones que suponían la paridad tomaban en cuenta caracteres permanentes. Por ello esta medida se consideró que no podría ser constitucionalmente admitida.

Otro argumento que se utilizó aludía a la vulneración de la distribución de competencias entre el Estado y las CCAA en materia electoral, dudando de la competencia del legislador autonómico para modificar el régimen electoral en el sentido de establecer la paridad de las candidaturas a los Parlamentos autonómicos. En este sentido puede leerse lo que en su día escribió Arce Janariz, a quien le llamaba poderosamente la atención que en las leyes electorales autonómicas no se hubieran mencionado, en su Exposición de motivos, a los títulos competenciales que hubiesen podido habilitarlas. Sostenía que queda reservado al legislador orgánico la regulación de los aspectos que constituían el núcleo duro del derecho de los partidos puesto que pocas facultades hay tan consustanciales a los partidos como la de formar listas y presentar candidaturas. Por consiguiente, mantenía que habría de ser la LOREG la que regulase los aspectos relativos a la elegibilidad y a las listas y candidaturas y que dichas previsiones habrían de ser las que se aplicasen a las CCAA como parte del régimen electoral general, por lo que le resultaba difícil de entender que las leyes autonómicas hubieran implantado cuotas de género sin aguardar a una modificación previa de la LOREG ${ }^{32}$. Resulta evidente que, tras la aprobación de la Ley Orgánica 3/2007, y la ulterior modificación del art. 44 bis LOREG, los argumentos esgrimidos en contra de las 'listas cremallera' en las elecciones autonómicas carecen de objeto al establecerse en el mismo que «En las elecciones de miembros de las Asambleas Legislativas de las Comunidades Autónomas, las leyes reguladoras de sus respectivos regímenes electorales podrán establecer medidas que favorezcan una mayor presencia de mujeres en las candidaturas que se presenten a las Elecciones de las citadas Asambleas Legislativas». Por ende, pasaremos a analizar el alcance del art. 44 bis LOREG.

31. Abellán Matesanz, I. M.: «La modificación de las leyes electorales a la luz del principio de igualdad: las «listas cremallera», REA, 23 (julio 2002, junio 2003), p. 155.

32. ARCE JANARIZ, A.: «Primeras leyes en España sobre paridad electoral», op.cit., p. 5 y ss. 
3.3. El principio de presencia o composición equilibrada del art. 44 bis LOREG y la JEC

Como hemos adelantado, en el art. 44 bis LOREG no se establece una cuota electoral a favor de las mujeres, ni siquiera plasma un tratamiento diferenciado en razón del sexo de los candidatos, por el contrario, el principio de presencia o composición equilibrada, consiste en que se garantice la presencia tanto de mujeres como de hombres en las listas electorales de forma que, en el conjunto a que se refiera, las personas de cada sexo no superen el $60 \%$ ni sean menos del 40\%. Como se puede leer en la Exposición de Motivos de la LO $3 / 2007^{33}$ :

«El llamado en la Ley principio de presencia o composición equilibrada, con el que se trata de asegurar una representación suficientemente significativa de ambos sexos en órganos y cargos de responsabilidad, se lleva así también a la normativa reguladora del régimen electoral general, optando por una fórmula con la flexibilidad adecuada para conciliar las exigencias derivadas de los 9.2 y 14 de la Constitución con las propias del derecho de sufragio pasivo incluido en el artículo 23 del mismo texto constitucional. Se asumen así los recientes textos internacionales en la materia y se avanza en el camino de garantizar una presencia equilibrada de mujeres y hombres en el ámbito de la representación política, con el objetivo fundamental de mejorar la calidad de esa representación y con ella de nuestra propia democracia.»

Por otro lado, la aplicación efectiva que del principio de presencia equilibrada de mujeres y hombres se nos propone: «en el conjunto de la lista los candidatos de cada uno de los sexos supongan como mínimo el cuarenta por ciento de la candidatura. (...) También se mantendrá la proporción mínima del cuarenta por ciento en cada tramo de cinco puestos». Es decir, entienden que la composición equilibrada queda asegurada con la presencia de dos mujeres entre las 5 primeras personas propuestas, si no se cumple este requisito, la candidatura no será proclamada.

Consideramos que la presentación y proclamación de candidaturas y candidatos se constituye en el momento que inicia una de las fases del proceso electoral más decisivas, tras la convocatoria de elecciones, y que dados los problemas planteados en la misma en las últimas elecciones municipales y autonómicas, en virtud de la aplicación del art. 44 bis LOREG, vamos a detenernos brevemente en su análisis. Regulada en el art. 44 y siguientes, el art. 187 y el art. 220 de la LOREG -dependiendo del tipo de elección de que se

33. Puede consultarse el trabajo de SEVILLA; J: «La participación política en la LO 3/2007 de 22 de marzo para la igualdad efectiva de mujeres y hombres», Repertorio Aranzadi del Tribunal Constitucional, 11 (2007), pp. 13-39. 
trate-, corresponde a la Junta Electoral competente atender la presentación de candidaturas, verificar -con la colaboración de los interesados- que los escritos cumplen todas las formalidades a fin de permitir subsanar todos los defectos subsanables y proceder a su proclamación ${ }^{34}$. Cabe plantearnos pues, cuáles son los defectos subsanables y si al respecto ha producido algún cambio la aprobación de la LO 3/200735.

Con carácter previo a la aplicación de los requisitos exigidos por el art. 44 bis LOREG, existía una doctrina consolidada de la JEC respecto a que la Administración Electoral estaba obligada a comunicar las irregularidades o los defectos de las candidaturas presentadas en el plazo establecido por la LOREG, sin perjuicio de las que pudieran ser denunciadas por los representantes de otras candidaturas ${ }^{36}$. Transcurrido el plazo establecido para la subsanación sin que el representante de la candidatura hubiese corregido debidamente las irregularidades puestas de manifiesto, la Junta Electoral competente no podía proceder a la proclamación ${ }^{37}$. Por su parte, el Tribunal Constitucional recuerda que la Administración electoral tiene el deber de poner en conocimiento de los componentes de las listas presentadas cualquier posible irregularidad al objeto de permitir su subsanación sin que pueda ser eludida mediante una distinción entre «irregularidades» $\mathrm{y}$ «defectos sustantivos» o «esenciales», distinción que no cuenta con base legal alguna y que resulta contradicha por la permisión que la propia ley hace (art. 48.1 LOREG) de la modificación de candidaturas a resultas de la subsanación y que desconoce, por lo demás, el principio interpretativo según el cual, la legalidad aplicable ha de ser entendida en los términos más favorables a la plena efectividad del derecho fundamental ${ }^{38}$.

Además, la Administración electoral tiene el deber de colaborar con los partidos para subsanar irregularidades, pues está en juego el derecho fundamental a acceder en condiciones de igualdad a los cargos públicos, que ha de recibir un trato respetuoso y favorable en el curso del proceso electoral ${ }^{39}$. En caso de que la Junta Electoral competente para la proclamación de candidaturas haya incumplido el deber de apreciación de oficio de los defectos y no

34. Ver García Soriano, M.V.: Jueces y Magistrados en el proceso electoral, Madrid, 2000, p. 250.

35 Sobre la conveniencia de llevar a cabo dichas reformas, puede consultarse MARTíNEZ VILA, P.: «Anteproyecto de LO de igualdad entre hombres y mujeres: el camino adecuado», Actualidad Administrativa, 12 (2006), pp. 1412-17.

36. AJEC de de mayo de 1987.

37. AAJEC de 11 de mayo e 1987, 16 de mayo e 1994, 24 de mayo de 1999.

38. STC 59/1987.

39. STC $86 / 1987$.

Feminismo/s 12, diciembre 2008, pp. 135-154 
haya dado ocasión a los interesados para la reparación de unas irregularidades que, más tarde, hayan conllevado el rechazo de las candidaturas, se habría ignorado una de las garantías previstas por la LOREG, en el art. 47.2, para la efectividad del derecho fundamental reconocido en el art. $23.2 \mathrm{CE}^{40}$.

Cuando, ante el Tribunal Constitucional, se planteó la duda de si el trámite de subsanación de irregularidades se podía utilizar para sustituir un candidato por otro, éste lo rechazó de manera tajante, tras admitir que dicho trámite también puede ser utilizado para corregir errores materiales, en el caso de sustitución de un candidato por otro no se había producido un error subsanable puesto que se había presentado una lista completa de candidatos, sin irregularidad ninguna, y lo que se pretendía era una modificación prohibida por el art. 48.1 LOREG $^{41}$. Tampoco cabe la posibilidad de que se modifique el orden en que aparecen los candidatos en la lista presentada en el trámite de subsanación ${ }^{42}$. Sin embargo, «la presentación de una candidatura de manera incompleta es un requisito subsanable, sin que por ello quepa hablar de presentación de una nueva candidatura ${ }^{43}$.

En cuanto a la exigencia establecida por el citado art. 44.1 bis LOREG, la introducción de la presencia equilibrada, las listas que no la respeten incurren en causa de inadmisibilidad, lo que supone una ampliación de las potestades de verificación y control de la Administración Electoral. Se ha considerado que de hecho, supone la «ilegalización de cualquier candidatura (con la consiguiente neutralización del partido afectado) que no respete las prescripciones legales» ${ }^{44}$. Y así, en efecto, el punto primero de la Instrucción 8/2007, de 19 de abril, de la Junta Electoral Central, sobre interpretación del trámite de subsanación de irregularidades previsto en el art. 48.1 LOREG por incumplimiento de los requisitos de los arts. 44 bis y 187.2 LOREG, en la redacción dada por la Ley Orgánica 3/2007, de 22 de marzo, para la igualdad efectiva de mujeres y hombres, establece que

«Durante el plazo de subsanación de las irregularidades advertidas por las Juntas Electorales competentes en las candidaturas presentadas, cuando la causa sea el incumplimiento de lo dispuesto en el artículo 44 bis de la LOREG o en la legislación autonómica aplicable sobre candidaturas paritarias, podrá modificarse el orden de los candidatos, o incluir o excluir algún candidato, siempre que con ello se trate estrictamente de subsanar la irregularidad

40. STC 24/1989, 175/1991.

41. Ver Sentencia 101/1991. Doctrina que fue consolidada en Sentencias posteriores.

42. STC $75 / 1995$.

43. STC $84 / 2003$.

44. Esta postura es mantenida, mutatis mutandis, por ARCE JANARIZ, A., «Primeras leyes en España...», op. cit. p. 4. 
apreciada, de conformidad con lo dispuesto en el último inciso del artículo 48.1 de la LOREG.»

La Instrucción 8/2007 supone, a nuestro juicio, una nueva interpretación de las previsiones contenidas en el art. 48 LOREG, que establece que

«una vez presentadas las candidaturas no pueden ser objeto de modificación, salvo en el plazo para subsanación de irregularidades previsto en el artículo anterior y sólo por fallecimiento o renuncia del titular o como consecuencia del propio trámite de subsanación.»

Hasta ahora, durante el plazo de subsanación de 48 horas, establecido por la Ley se permitía la modificación sólo para los supuestos contemplados en el art. 47 LOREG, de modo que se planteaba el problema de si los representantes de las candidaturas podían modificar éstas -sustituir candidatos o modificar el orden de las listas- durante el plazo de subsanación de irregularidades por causas distintas al fallecimiento o la renuncia de su titular.

4. El principio de presencia equilibrada cuestionado por el recurso de inconstitucionalidad n.5653-2007 y la cuestión de inconstitucionalidad n.4069-2007

Recordemos que la modificación de la LOREG introducida por la Disposición Adicional Segunda de la LO 3/2007, que modificó el art. 44 bis en la LOREG no establece una medida de discriminación inversa o compensatoria sino una fórmula de equilibrio entre sexos que tampoco es estrictamente paritaria (no impone una total igualdad sino la regla de que unos y otras no podrán integrar las candidaturas electorales en una proporción inferior al 40\%). Su efecto resulta bidireccional: afecta a uno y a otro sexo. Tras la denegación de la proclamación de algunas candidaturas por no cumplir las condiciones impuestas por la LOREG, el 10 de mayo de 2007, el Tribunal Constitucional rechazó un recurso de amparo presentado por el PP contra la prohibición de concurrir a las elecciones en Garachico (Tenerife) con una lista compuesta sólo por mujeres. El argumento del Alto Tribunal consistía en que debía resolver la cuestión de inconstitucionalidad núm 4069-2007, promovida por el Juzgado de lo Contencioso Administrativo número 1 de Santa Cruz de Tenerife en relación con la Ley Orgánica 3/2007. En este, el magistrado cuestionaba si el artículo 44 bis LOREG, redactado por la Disposición Adicional Segunda de la LO 3/2007, que recoge las listas paritarias, era contrario, o no, a la Constitución. Posteriormente también se presentó un recurso de inconstitucionalidad, núm 5653-2007, que fue acumulado a la anterior cuestión, promovido por más de cincuenta diputados del Grupo Parlamentario Popular en el Congreso de los Diputados. 
La controversia generada por las previsiones contenidas en la LO 372007 no era de extrañar, pues no resulta insólito que se cuestione la constitucionalidad de las medidas que favorezcan la igualdad en el acceso a los cargos representativos, allí donde se han introducido, para hacer efectivo el principio de igualdad material. Citemos algunos ejemplos: el Consejo Constitucional francés rechazó en dos ocasiones ${ }^{45}$ una reserva del $25 \%$ de puestos para mujeres en las listas de candidatos. En Italia, la Corte Constitucional, en su Sentencia 422 de 12 de septiembre de 1995 declaró contraria a diversos preceptos constitucionales la regulación electoral del año 1993 que establecía que ninguno de los dos sexos podría estar presente en las listas en un porcentaje superior a los $2 / 3$ respecto del otro ${ }^{46}$. Son sentencias que suelen citarse por los

45. En 1982 se aprobó la reforma de la Ley reguladora de las elecciones municipales en que se estableció una cuota del $25 \%$ para las mujeres. Recurrida la media ante el Consejo Constitucional que declarada inconstitucional por su incompatibilidad con el principio de igualdad. A posteriori, el 28 de junio de 1999 se modificó el art. 3 de la Constitución francesa lo que posibilitó que se reformara la legislación electoral, que estableció la paridad en las listas electorales, legislación que se aplicó en las elecciones municipales de 2001.

El motivo que adujo el Consejo Constitucional fue que el tenor literal del art. 3 de la Constitución francesa dispone que «todos los representantes son iguales ante la ley sin que quepa más distinción que su virtud o talento». Vid. FAVOrEU, L.: «Principio de igualdad y representación política de las mujeres. Cuotas, paridad y Constitución», REDC, 17 (1997).

En la actualidad dicho precepto ha sido modificado de modo que su dicción literal ha pasado a ser «la ley favorecerá la igualdad entre hombres y mujeres para acceder a los mandatos electorales y cargos electivos». A su vez, el art. 4 dispone que los partidos y las agrupaciones políticas (...) contribuirán a la aplicación del principio enunciado el último apartado del art. 3 de acuerdo con lo dispuesto por la ley.

En el caso francés, al ser las listas uninominales, los partidos han de presentar, del número total de candidatos un $50 \%$ de cada sexo, siendo penalizados si la disparidad de candidatos es superior al $2 \%$.

46. La Corte Constitucional sostuvo que tanto el art. 3.c.1. como el 51.c.1 afirmaban que en el acceso a los cargos públicos se debía operar con una aplicación rigurosa del principio de igualdad que no podía tener un significado diverso a la indiferencia del sexo a los fines considerados y no era casual que en el acceso a los cargos públicos, el art. 51.c.1 no se limitase a reconocer este derecho a todos los ciudadanos sino que se especificaba «de uno y otro sexo» Consideró inconstitucional la introducción de las cuotas porque en materia electoral la regla establecida por el constituyente era la absoluta paridad por lo que cualquier diferenciación en razón del sexo no podía ser sino discriminatoria. Además, consideraba que tal medida no era una acción positiva sino una discriminación inversa porque ante la imposibilidad de un determinado grupo de lograr un determinado bien, este último se atribuía directamente al sujeto desfavorecido. Sustancialmente afirmaba que el legislador no podía intervenir, pues en materia electoral prevalecía la igualdad formal.

Ver al respecto CECCERINI, E.: «La igualdad de sexos en la representación política. La experiencia italiana», REDCE, 6 (2006), pp. 340 y ss.

Feminismo/s 12, diciembre 2008, pp. 135-154 
detractores de las cuotas o las medidas para establecer la presencia equilibrada en las listas. Sin embargo, insistimos en recordar que existe una diferencia fundamental respecto del caso español: en ambos casos las respectivas Constituciones, con carácter previo a las reformas acaecidas, adolecían de una falta de definición de la igualdad material, lo que hizo necesarias la reforma constitucional, al igual que también se llevaron a cabo reformas constitucionales para la introducción de cuotas lectorales en Alemania, Portugal o Bélgica ${ }^{47}$.

Pero volviendo al caso español, recordemos cuáles fueron los hechos: en las pasadas elecciones municipales, la Junta Electoral de Zona (JEZ) denegó la proclamación de las listas del PP en el municipio de Garachico por estar integrada únicamente por mujeres y, en lugar de proceder a la subsanación, dentro del plazo previsto por la LOREG, el representante de la candidatura alega que ésta era conforme con la Constitución y no cabía subsanación alguna, por lo que la candidatura no fue proclamada por la JEZ. La resolución de la JEZ fue objeto de recurso contencioso-electoral. En la demanda se solicitaba, por medio de otrosí, el planteamiento de una cuestión de inconstitucionalidad. El Juez elevó una cuestión de inconstitucionalidad en la que se duda de la conformidad con la Constitución del art. 44.bis de la LOREG por las razones que pasamos a resumir:

1-Porque las previsiones que establecían la presencia equilibrada de ambos sexos en las listas electorales en un porcentaje del $40 \%-60 \%$, vulneraban el art. 23.2 CE en el que se establece que se accederá en condiciones de igualdad a cargos representativos.

2-El principio de igualdad ante la ley, art. $14 \mathrm{CE}$, impide que el legislador de un trato distinto a las personas que se encuentren en la misma situación y el art. 9.2 CE establece la obligación de los Poderes Públicos de promover la igualdad real. Sin embargo, lo que en la cuestión se califica como «discriminación positiva», que en teoría debería beneficiar a las mujeres, les perjudica porque únicamente permite que estas puedan alcanzar un $60 \%$ de puestos en las listas.

3-El equilibrio que se refleja en el art. 44 bis LOREG no se refleja en la Constitución. Además, dicho precepto restringe la libertad de los partidos a la hora de decidir quiénes van a integrar las candidaturas, impidiendo con ello la legítima aspiración de las mujeres a lograr una abrumadora presencia en las listas.

Sin embargo, años después, la Constitución italiana fue objeto de dos reformas, en 2001 y 2003. En la Sentencia de la Corte Constitucional 49 de 2003, la Corte declara la obligación de presentar candidatos de ambos sexos afirmando que la orientación de la Sentencia 422 de 1995 había sido ampliamente superada.

47. En Bélgica desde el año 99 se establece una cuota del 33\% de mujeres en todas las listas. Si dicha exigencia no se cumple, los puestos que corresponderían a las mujeres se consideran en blanco. 
En cuanto al recurso de inconstitucionalidad, presentado el 21 de junio de 2007, promovido por diputados del Grupo Parlamentario Popular, tras celebrarse las elecciones municipales y autonómicas, se fundamentaba en los siguientes motivos:

El art. 44 bis LOREG vulnera el art. 23 CE pues con la reforma introducida por la LOI se alteraba el sistema electoral español. La categoría de ciudadano es indivisible a efectos de su elegibilidad, por lo que el legislador carece de base jurídica para establecer diferencias en su seno. El legislador electoral ha de ser neutral en cuanto a la raza, sexo, religión... teniendo vedada toda discriminación positiva. Los ciudadanos se verían afectados cuando ya se hubiese agotado su «cupo». Si la mitad femenina de la ciudadanía tuviera que verse reflejada en las candidaturas, también lo tendrían que ser otras categorías: ancianos, discapacitados.

El art.44 bis LOREG vulnera el art. 14 CE. Si dentro del campo de la igualdad caben acciones positivas de acuerdo con el art. 9.2 CE, la intervención del poder público ha de cesar cuando se garantiza la igualdad en el punto de partida; las medidas han de eliminar/compensar las situaciones de desigualdad, pero no pueden incidir en el contenido de los derechos. Las cuotas hacen que quienes pretendan formar parte de una candidatura no puedan hacerlo por el simple hecho de que su sexo ha cubierto el cupo establecido.

Asimismo se consideraron vulnerados otros preceptos constitucionales: el art. $6 \mathrm{CE}$ en relación con el art. 22.1, por imponer dichas medidas una restricción a la libre actividad de los partidos políticos en la formación de las candidaturas; el art. 68.5, porque en éste el constituyente no distingue entre categorías de personas; el art. 16.1 CE en relación con la libertad ideológica y de difusión del propio pensamiento por parte de las personas o partidos; el art. 20.1.a) al impedir que existan candidaturas sólo de hombres o sólo de mujeres para defender ante la sociedad lo que estimen pertinente.

\section{La STC 12/2008 y la participación equilibrada}

El Tribunal Constitucional acumuló el recurso y la cuestión de inconstitucionalidad y resolvió ambos en la STC 12/2008. El Alto Tribunal recuerda que la igualdad material recogida en el art. 9.2 CE, se proyecta en el ámbito de la representación política, perspectiva propia de la caracterización de un Estado como social y democrático de derecho que, junto con los valores del art. 1.1 $\mathrm{CE}$ son el fundamento axiológico del orden constitucional y deja claro desde el principio que la LO 3/2007 no incorpora fórmulas compensatorias a favor de las mujeres en su calidad de grupo desfavorecido sino que plasma un criterio que se refiere indistintamente a los candidatos de uno y otro género. La participación equilibrada no supone un tratamiento peyorativo de ninguno de los dos sexos, pues, ni siquiera se plasma un tratamiento diferenciado por 
sexos sino que atiende al criterio del sexo, que, de manera universal, divide a toda la población en dos grupos porcentualmente equilibrados ${ }^{48}$.

Con todo, cuando el Alto Tribunal ha de conocer de una medida que pretendidamente resulta discriminatoria, aplica el conocido test de igualdad sobre la medida para averiguar si el fin de la misma es legítimo, si es razonable y si es proporcionada en relación con la finalidad perseguida, determinando que el porcentaje establecido sólo excluye a las candidaturas que ni siquiera aceptan integrar a los ciudadanos de uno u otro sexo. Resulta inocuo para los derechos fundamentales, pues es una medida cuyo destinatario son los partidos políticos que no son los titulares del derecho de sufragio y, resulta proporcionada al ser un mandato de equilibrio entre sexos en la presentación de candidaturas. De este modo, el desequilibrio histórico entre mujeres y hombre en las candidaturas ya no hace falta que sea compensado por candidaturas totalmente femeninas.

Según el Tribunal, el art. 44 bis LOREG busca la efectividad del art. 14 CE en la representación política, dado que, a pesar de que las mujeres y los hombres son formalmente iguales, las primeras han estado preteridas y la ley se sirve de los partidos que han de hacer realidad la igualdad material del 9.2 CE con la efectiva incorporación de la mujer a las Cámaras o a las Corporaciones. Ello podría colisionar con la libertad de los partidos para confeccionar las candidaturas, pero esta libertad ni es un derecho fundamental ni es absoluta sino que la LOREG ya incluye ciertas exigencias: las condiciones de elegibilidad de los candidatos (que incluye la residencia en algunas leyes autonómicas), que se presente un número determinado de candidatos, que las listas sean cerradas y bloqueadas, por lo que la exigencia del $40 \%-60 \%$ se convierte en otra limitación más.

En la STC 12/2008, el Tribunal Constitucional reitera que el art. 23.2 CE no incorpora un derecho a ser proclamado como candidato a unas elecciones $^{49}$, por tanto, las previsiones contenidas en la LOREG no quebrantan el derecho de sufragio pasivo cuyo contenido es la garantía de que accedan al cargo los ciudadanos que han sido elegidos ${ }^{50}$, permanezcan en el mismo, etc. Ni del art. 23.1 CE se infiere ningún derecho subjetivo de los ciudadanos a una concreta composición de las listas electorales.

48. Puede consultarse, Biglino Campos, P.: «Variaciones sobre las listas de composición equilibrada (Comentario a la STC 12/2008)», REDC, 83 (2008); LOUSADA AROCHENA, J. F: «Unos apuntes sobre las llamadas cuotas electorales a la vista de la declaración de su constitucionalidad», La Ley, 6918 (2008).

49. Vid. STC 78/1987.

50. Entre otras, STC 154/2003.

Feminismo/s 12, diciembre 2008, pp. 135-154 
En cuanto a la alegada fragmentación del cuerpo electoral (que está sometido a la Constitución y al resto del ordenamiento jurídico (art. 9.1 CE), el TC considera que la composición equilibrada de las listas no quiebra la unidad de la categoría de ciudadano porque no compartimentan el cuerpo electoral en función del sexo. Los candidatos defienden opciones políticas diversas y representan al electorado en su conjunto y no en función de su sexo.

Tampoco afecta a la libertad ideológica pues no impone a las candidaturas una determinada ideología, la presencia equilibrada es sólo otro requisito para la formación de las listas; sin embargo, aunque se produjese una limitación de los derechos reconocidos en los arts. 16.1 CE y 20.1.a) CE tal limitación habría de entenderse constitucionalmente legítima porque resultaría proporcionada.

Para concluir, recordaremos que el requisito exigido en el art. 44 bis LOREG no se trata de una medida de acción positiva, ni de una cuota electoral sino de un instrumento constitucionalmente legítimo para hacer efectiva la igualdad material reconocida en el art. 9.2 CE y garantizar el acceso de la mujer a los cargos públicos representativos, así como el reparto equilibrado del poder entre los sexos ${ }^{51}$; sin embargo, la realidad evidencia que en las instituciones más cercanas al ciudadano, la presencia de la mujer, si bien es significativa en asociaciones vecinales, los municipios de menor entidad son, por lo general, aquellos que cuentan con menor representación femenina. Ello no obstante, en la LOI se excepciona a las candidaturas presentadas en las elecciones locales de los municipios de menos de 5.000 habitantes (de 3.000 a partir de año 2011) o en islas con menos de 5.000 residentes. Se excluyen de esta obligación las candidaturas que se presenten en los municipios o islas con un número de residentes igual o inferior a 5.000 habitantes. En España existen cerca de 5.800 municipios con población inferior a la citada, de una cifra total de unos 8000 municipios que componen la geografía española. Por consiguiente, se deja fuera al $70 \%$ de municipios, de modo que la mayoría de las candidaturas de nuestro Estado quedarían exceptuadas de tener que cumplir el requisito democrático de participación política atendiendo al principio de presencia equilibrada.

El TC considera que esta excepción es posible desde el momento en que el art. 9.2 CE no obliga a que los instrumentos para la consecución de la igualdad material se apliquen a todos los casos, dejando al legislador flexibilidad a la hora de determinar si las condiciones en esos municipios de reducida

51. Vid. al respecto, Astola, J.: «El acceso de las españolas a los cargos públicos representativos», Artículo 14. Una perspectiva de género, 27 (2008). 
población aconsejan que las candidaturas respeten el principio de presencia equilibrada.

Si atendemos a que la aplicación de las previsiones analizadas apenas han supuesto cambios respecto al acceso de la mujer a los cargos públicos representativos y a que, con las exclusiones previstas en la LO 3/2007, la mayoría de las candidaturas estarán exentas del cumplimiento del requisito de participación equilibrada, no creemos que haya motivos como para pensar que será suficiente con las medidas adoptadas hasta el momento. 